\title{
REVIEW
}

\section{Antimicrobial Stewardship from Policy to Practice: Experiences from UK Antimicrobial Pharmacists}

\author{
Mark Gilchrist · Paul Wade · Diane Ashiru-Oredope · Philip Howard • \\ Jacqueline Sneddon · Laura Whitney · Hayley Wickens
}

To view enhanced content go to www.infectiousdiseases-open.com

Received: July 20, 2015 / Published online: September 11, 2015

(C) The Author(s) 2015. This article is published with open access at Springerlink.com

\begin{abstract}
Antimicrobial stewardship in the UK has evolved dramatically in the last 15 years. Factors driving this include initial central funding for specialist pharmacists and mandatory reductions in healthcare-associated infections (particularly Clostridium difficile infection). More recently, the introduction of national stewardship guidelines, and an increased focus on stewardship as part of the UK five-year antimicrobial resistance strategy, have accelerated and embedded developments. Antimicrobial pharmacists have been
\end{abstract}

M. Gilchrist ( $\square)$

Imperial College Healthcare NHS Trust, Charing Cross Hospital, Fulham Palace Road, London W6 8RF, UK

e-mail: mark.gilchrist@imperial.nhs.uk

P. Wade

Guy's and St. Thomas' NHS Foundation Trust, St

Thomas' Hospital, Westminster Bridge Road,

London SE1 7EH, UK

D. Ashiru-Oredope

Antimicrobial Resistance Programme, Public Health

England, London, UK

P. Howard

Leeds Teaching Hospitals NHS Trust, Great George

Street, Leeds LS1 3EX, UK instrumental in effecting changes at an organizational and national level. This article describes the evolution of the antimicrobial pharmacist role, its impact, the progress toward the actions listed in the five-year resistance strategy, and novel emerging areas in stewardship in the UK.

Keywords: Antibiotic;

Antimicrobial stewardship; Healthcare-associated infections; Pharmacy; Resistance

\footnotetext{
J. Sneddon

Scottish Antimicrobial Prescribing Group, Healthcare Improvement Scotland, 50 West Nile Street, Glasgow G1 2NP, UK

L. Whitney

St George's University Hospital NHS Foundation Trust, Blackshaw Road, Tooting, London SW17 0QT, UK

H. Wickens

University Hospital Southampton NHS Foundation Trust, Southampton General Hospital, Tremona Road, Southampton SO16 6YD, UK
} 


\section{THE DEVELOPMENT OF ANTIMICROBIAL STEWARDSHIP IN THE UK: EARLY DAYS AND DRIVERS}

In the early part of this century, the UK government focused heavily on reducing the incidence of healthcare-associated infections (HCAIs) [1, 2], such as methicillin-resistant Staphylococcus aureus (MRSA) bacteremias and Clostridium difficile infections (CDI). A combination of voluntary, followed by mandatory, reporting of these infections allowed the National Health Service (NHS) to identify and monitor the scale of the problem, and then to develop actions to improve outcomes [3]. The peak incidence of MRSA bacteremias was seen in 2003, at 7700 cases, and for CDI the peak was seen in 2007, with 57,247 cases reported [4]. In response to these high levels, NHS hospital Trusts were set targets (with large financial penalties for failure) to reduce MRSA bacteremias by $50 \%$ by 2008 and CDI by 30\% by 2010-2011 [5, 6].

At around the same time, antimicrobial stewardship (AMS) began to evolve rapidly when, in 2003, the Department of Health announced a three-year Hospital Pharmacy Initiative, complete with $£ 12$ million of funding for hospital pharmacies, aimed at improving the monitoring and control of anti-infectives [7], with a view to contributing to the efforts to tackle HCAIs. This thrust pharmacists into a key role in AMS with the majority of this money being spent creating antimicrobial pharmacist positions [8]. Immediate outcomes from this initiative were widespread update and revision of local antimicrobial guidelines, increasing interaction between Microbiology/Infectious Diseases and Pharmacy (leading to development of, or more frequent, joint ward rounds), and a dramatic increase in the provision of education and training to healthcare professionals in prudent antimicrobial use $[8,9]$. These interventions have been associated with improved antimicrobial usage, reductions in length of stay, and improved clinical outcomes (such as reductions in CDI) [10-14], and both of the high-level objectives for MRSA bacteremias and CDI cases were met with $57 \%$ and $41 \%$ reductions, respectively.

At the core of these reductions (most obviously for CDI) was improved antibiotic prescribing. Initial guidance documents around management of CDI recommended enhancing AMS, including: dedicated teams; using narrow spectrum antibiotics for empiric treatment where appropriate; avoiding the use of clindamycin and second- and third-generation cephalosporins, especially in the elderly; and minimizing the use of fluoroquinolones, carbapenems and prolonged courses of aminopenicillins [15-19]. Antimicrobial pharmacists have continued to play an integral role in developing and managing antimicrobial guidelines, reviewing individual patient regimens to optimize therapy, educating healthcare staff on the appropriate use of antimicrobials and monitoring and auditing outcomes of antimicrobial usage across organizations.

There has been a continued impressive $77 \%$ reduction in CDI cases from 108 cases per 100,000 population (in 2007-2008) to 25 cases in 2013-2014 [4]. Further developments in CDI objective setting now include a consideration of the avoidability of the case and whether there have been any "lapses in care" leading to the episode [20]. Although it is not discretely defined as such, inappropriate antimicrobial usage would be recognized as a "lapse in care", and antimicrobial pharmacists continue to be heavily involved in optimizing therapy, 
preventing CDI cases, and investigating them and sharing relevant learning when they occur.

In Scotland, similar targets, but without financial penalties, were set for the reduction of $S$. aureus bacteremia and CDI [21] which have resulted in similar significant reductions to those seen in England [22]. The national stewardship program led by Scottish Antimicrobial Prescribing Group (SAPG) has brought about reduced use of antibiotics associated with a high risk of CDI and this is acknowledged as a major factor in reducing the CDI rate [23].

\section{MORE RECENT DEVELOPMENTS IN UK STEWARDSHIP GUIDELINES AND STRATEGY}

To better develop and standardise the stewardship strategy, official guidance and toolkits have recently been issued in the UK for community (primary) care in 2012 [24] and hospital (secondary) care, firstly in 2011 and very recently updated in 2015 [25, 26].

In 2013, a cross-government five-year antimicrobial resistance (AMR) strategy was published which takes a 'One Health' approach to tackling AMR [27]. This outlined seven key areas for action (Table 1) and recommended that, for the first time, an implementation plan and yearly progress reports be published. As healthcare in the UK is devolved into four different national services (England, Scotland, Wales and Northern Ireland) each nation has a committee, which oversees stewardship (Table 2). These groups are largely responsible for ensuring progress toward the AMR strategy and all have significant pharmacist input.

To date, antimicrobial pharmacists have had most involvement in three of the key areas
Table 1 UK antimicrobial resistance strategy: seven key areas for action

Better access to and use of surveillance data

Optimizing prescribing practice

Improving infection prevention and control

Improving professional education, training and public engagement

Improving the evidence base through research

Developing new drugs, vaccines and other diagnostics and treatments

Strengthening UK and international collaboration

highlighted in the UK AMR strategy, which are discussed in detail below. Antimicrobial pharmacists have a smaller role in infection prevention and control by providing pharmaceutical expertise to infection control committees and infection prevention and control teams. Also, increasing work is being carried out to improve the evidence base through research into stewardship and to strengthen UK and international collaboration. Developing new compounds or vaccines for use in clinical practice, and the introduction of other diagnostics and treatments is usually beyond the remit of their work.

\section{Better Access To, and Use of, Surveillance Data}

Feedback of consumption data is a key element of an AMS program [28]. In order to engage prescribers, data are needed [29] and lack of it is a barrier to effective implementation of AMS $[30,31]$. In the UK, consumption data have been available since 1991 for community prescribers. It is captured as part of the reimbursement of community pharmacists for dispensing NHS prescriptions [32], but will not include antibiotics supplied by any other 
Table 2 National groups responsible for the overview of stewardship

\begin{tabular}{|c|c|c|c|}
\hline Nation & Group & $\begin{array}{l}\text { Date } \\
\text { formed }\end{array}$ & Remit \\
\hline \multirow[t]{2}{*}{ England } & $\begin{array}{l}\text { Antimicrobial Stewardship subgroup (ASG) } \\
\text { of the Advisory Committee on } \\
\text { Antimicrobial Resistance and } \\
\text { Healthcare-Associated Infection (ARHAI) }\end{array}$ & 2003 & $\begin{array}{l}\text { Established as part of the Specialist Advisory } \\
\text { Committee on Antimicrobial Resistance } \\
\text { (SACAR), to focus on the prudent prescribing of } \\
\text { antimicrobials across the National Health Service } \\
\text { (NHS) }\end{array}$ \\
\hline & $\begin{array}{l}\text { English Surveillance Program for } \\
\text { Antimicrobial Utilization and Resistance } \\
\text { (ESPAUR) }\end{array}$ & 2013 & $\begin{array}{l}\text { Developed by Public Health England (PHE) to } \\
\text { bring together antimicrobial utilization and } \\
\text { resistance data, examine national implementation } \\
\text { of stewardship initiatives and develop quality } \\
\text { measures, methods to monitor unintended } \\
\text { outcomes of antimicrobial stewardship and both } \\
\text { public and professional behavior interventions }\end{array}$ \\
\hline Scotland & $\begin{array}{l}\text { Scottish Antimicrobial Prescribing Group } \\
\text { (SAPG) }\end{array}$ & 2008 & $\begin{array}{l}\text { To lead and coordinate delivery of the Scottish } \\
\text { Management of Antimicrobial Resistance Action } \\
\text { Plan (ScotMARAP) [83] }\end{array}$ \\
\hline Wales & $\begin{array}{l}\text { Welsh Antimicrobial Resistance Program } \\
\text { Surveillance Unit (WARP-SU) }\end{array}$ & 2008 & $\begin{array}{l}\text { Currently focuses on reporting antimicrobial usage } \\
\text { and resistance data and coordinating nationwide } \\
\text { antimicrobial audits }\end{array}$ \\
\hline $\begin{array}{l}\text { Northern } \\
\text { Ireland }\end{array}$ & $\begin{array}{l}\text { Antimicrobial Resistance Action Committee } \\
\text { (ARAC) }\end{array}$ & 2002 & $\begin{array}{l}\text { ARAC provides expert advice to the Department of } \\
\text { Health, Social Services and Public Safety } \\
\text { (DHSSPS) on all issues to do with antimicrobial } \\
\text { resistance and provides leadership on strategies for } \\
\text { tackling this issue. Strategy for Tackling } \\
\text { Antimicrobial Resistance (STAR) 2012-2017 [84] }\end{array}$ \\
\hline
\end{tabular}

method, e.g. private prescriptions or packs given out in clinics. The data are used to compare rates of prescribing within localities using a standardized method to account for differences in the local population. For example, the use of Specific Therapeutic Group Age-sex weightings Related Prescribing Units (STAR-PUs) as a denominator allows more accurate and meaningful comparisons within a specific therapeutic group by taking into account the types of people who will be receiving that treatment [33]. These data can be used to drive improvements in antimicrobial prescribing rates, total antibiotic consumption and broad-spectrum antibiotic consumption (cephalosporins, fluoroquinolones and amoxicillin/clavulanate) [34, 35]. From 2005 until 2013, overall antimicrobial consumption had been increasing in the community, but significant reductions were seen in the use of cephalosporins and fluoroquinolones [32]. Although there has been no explicit linkage between increasing AMR rates and increasing consumption of specific antimicrobials or classes, in 2014, the Department of Health's expert advisory committee, the Advisory Committee on Antimicrobial Resistance and Healthcare Acquired Infections (ARHAI), 
proposed that total antimicrobial consumption should reduce to 2010 levels in the community $[36,37]$ and that the proportion of antibiotics from cephalosporin, quinolone or amoxicillin/clavulanate classes should reduce by $10 \%$ from the $2013 / 2014$ value or to less than the 2013/2014 median, whichever is the smaller reduction. In 2015-2016, a Quality Premium [38] (financial reward) was introduced to achieve this goal, along with a national reporting tool to monitor it [39].

In Scotland, a similar national quality indicator was introduced in 2013 aimed at reducing unnecessary antibiotic use for self-limiting respiratory infections. This uses a 'best in class' approach so that at least $50 \%$ of practices in each region will be at or below the 25th percentile of Scottish practices (using January-March 2013 as the baseline) or will have made the minimum acceptable reduction toward that level. In 2013-2014, there were 276,383 (6.5\%) fewer prescriptions for systemic antibacterials in primary care in Scotland than in $2012-2013$ and $57.5 \%$ of practices achieved the national quality indicator. Since 2008, there has been a focus on reducing the use of cephalosporins, quinolones and amoxicillin/clavulanate in the community and this has led to year-on-year reductions in the use of these agents [40].

For English hospitals, a detailed and comprehensive report published by the English Surveillance Program for Antimicrobial Utilization and Resistance (ESPAUR), set up by Public Health England in response to the five-year AMR strategy, provided the very first national data on antimicrobial consumption [41]. This report covered the period 2010-2013 and used consumption data derived from hospital pharmacy stock management systems for drugs dispensed to both individual patients and ward stocks. This type of data has to be used because electronic prescribing (EP) in hospitals in England is very much in its infancy [41]. Using hospital pharmacy stock management systems prevents the reporting of detailed consumption data down to doctor or clinical team level, and neither of the two main pharmacy accounting systems used in the UK includes a reporting tool as standard. A worldwide survey of hospital AMS showed that $92 \%$ of UK hospitals reported antimicrobial usage data, but only $52 \%$ reported defined daily doses (DDDs) to specialty level, and even fewer were able to link consumption data to resistance or infection rates (31\% and 33\%, respectively) $[42,43]$.

The ESPAUR report [41] showed an increase in overall antibiotic consumption in hospital inpatients of $11.9 \%$ over the 4 -year period (an average year-on-year increase of $3.5 \%$, equivalent to 2.3-2.5 DDD per 1000 inhabitants per day). The data were reported at area level only, so did not allow benchmarking between hospitals.

ARHAI in England also proposed (although these proposals may be subject to further refinement) that total antibiotic consumption be reduced by 1\% per annum over 2015-2019 (as measured by DDD per 1000 admissions per year), and total carbapenem consumption be reduced to 2010 consumption levels (as measured by the same method), corresponding to an average reduction of $20-25 \%$ [36, 37]. Again, there has been no explicit linkage between increasing antimicrobial consumption and increasing AMR, but the ESPAUR report does show increases in both elements over the reporting period, and controlling antimicrobial consumption is recognized as a key element of the AMR strategy [41]. In 2015-2016, consumption data are being validated by hospitals as part of the Quality Premium [38]. In addition, $65 \%$ of NHS hospitals are also using a specific software package (Rx-Info Define) to 
benchmark hospital medicines consumption [44].

Since 2008, SAPG has published annual reports on antimicrobial use and resistance in humans [45] utilizing national data marts which collate data from hospital Pharmacy and Microbiology systems and prescriptions for antibiotics dispensed by community pharmacists. In Wales, the Welsh Antimicrobial Resistance Program Surveillance Unit (WARP-SU) [46] currently reports antimicrobial usage and resistance data. Finally, within Northern Ireland, the COMPASS system [47] provides data on primary care antibiotic prescribing with the national AMR dataset currently being developed.

\section{Optimizing Prescribing Practice}

There are two national AMS toolkits for England: Start Smart then Focus for hospital care [25, 26] and the Treat Antibiotics Responsibly, Guidance, Education, Tools (TARGET) Antibiotics toolkit for community care [24]. Wales [48] and Scotland [49] have their own versions of the guidance. In addition, national guidance on AMS is due for publication in August 2015 by the National Institute for Health and Care Excellence (NICE) [50].

The Scottish Antimicrobial Prescribing Group has produced national guidance [49] on AMS and infection management to support antimicrobial teams and prescribers across hospital and community care settings. All regions have a centrally funded antimicrobial pharmacist position in addition to locally funded positions to support local delivery of stewardship and drive quality improvement in antimicrobial prescribing.

A large proportion of antimicrobial pharmacist time is currently dedicated to optimizing prescribing practice, as described later in this article.

\section{Improving Professional Education, Training and Public Engagement}

Education and training is essential to optimizing prescribing and AMS, and, in order to drive consistency in practice, performance standards need to be set. The first national antimicrobial prescribing and stewardship competences were published in 2013 and these are currently being developed to include in Health Education England work streams [51]. The competences consist of five dimensions, and each dimension includes statements that describe the activity and outcomes that prescribers should be able demonstrate. The five dimensions are:

1. Infection prevention and control.

2. AMR and antimicrobials.

3. The prescribing of antimicrobials.

4. AMS.

5. Monitoring and learning.

Antimicrobial pharmacists are central to the delivery of education on stewardship for healthcare staff, and in 2014 an expert curriculum [52] was developed to support specialist Infectious diseases and antimicrobial pharmacists in this role, as well as providing professional development opportunities. The 4-year pharmacy degree contains variable amounts of teaching and training in AMS and there are limited postgraduate opportunities for pharmacists to gain specialist training in infection management and AMS [53]. The expert curriculum provides the first opportunity to develop some form of credentialing in this area.

The TARGET antibiotic toolkit [24] includes educational materials for prescribers in primary care. A similar initiative has also been developed in Wales: the 'Stemming the Tide of Antibiotic Resistance' educational program (STAR) $[54,55]$. This includes resources for 
clinicians to share with the public during consultations and is reported to have helped deliver changes in local prescribing practices and reduce unnecessary antibiotic use [56]. In Scotland, a similar program, the Scottish Reduction in Antimicrobial Prescribing (ScRAP) [57], was launched in October 2013 as an educational resource to help prescribers to meet a government target to reduce unnecessary prescribing of antibiotics. In 2015, SAPG, in collaboration with NHS Education for Scotland, launched a stewardship resource for nurses and midwives in the form of an interactive electronic workbook [58].

Since 2008, the UK has actively promoted 'European Antibiotic Awareness Day' (EAAD) which is held in November each year to raise awareness among health professionals and the public of AMR and appropriate prescribing and antimicrobial use. In 2014, to move from raising awareness to engagement, and as a marker for behavior change, a new campaign, Antibiotic Guardian, was developed which called on everyone in the UK to choose a pledge on the website http://www. antibioticguardian.com. The pledges were developed using the behavior change strategy 'if-then' approach. In the first two months, 11,998 healthcare professionals and members of the public chose a pledge and became antibiotic guardians.

\section{HOW DOES THE PHARMACIST FUNCTION WITHIN STEWARDSHIP TEAMS?}

In 2011, English hospitals reported employing an average of one full-time antimicrobial pharmacist per 776 inpatient beds, representing approximately 3\% of the clinical pharmacists in those organizations [59]. These pharmacists vary in seniority, and often combine their antimicrobial duties with other responsibilities such as respiratory or intensive care specialist roles [59]. The typical activities of antimicrobial pharmacists in hospitals have been well described in the literature, and are shown in Table 3 [8, 9, 41, 59-62]. Key to all of

Table 3 Typical activities of UK antimicrobial pharmacists

Production and dissemination of evidence-based prescribing guidelines and prescribing policies, increasingly utilizing technology such as smartphone 'apps' and electronic training packages

Education of prescribers, pharmacy and nursing staff in the prudent use of antimicrobials, including mandatory induction training for all staff

Providing a clinical advice service, often with access via a pager, supporting prescribers in optimizing antimicrobial therapy for individual patients, and providing input on multidisciplinary infection ward rounds

Advising on therapeutic drug monitoring for antimicrobials

Monitoring and feedback of trends in antimicrobial prescribing, formulary and guideline adherence to clinical teams, and inputting into governance structures within organization. Point prevalence surveys of antimicrobial use, conducted at least annually, are widespread in the UK, though an increasing number of hospitals are using rapid feedback of quality indicator measures to drive improvements in antimicrobial prescribing [14]

Managing entry of new antimicrobials onto hospital formularies, including critical review of new agents and their place in therapy

Clinical research, both in support of drug registration studies, and in novel research to consolidate the evidence base around antimicrobial stewardship 
this activity is the well-established linkage between AMS pharmacists and their microbiologist/infectious diseases colleagues, which allows both specialties to share and contribute to optimizing patient care. Also, due to the patient load and their other responsibilities, antimicrobial pharmacists in the UK rely heavily on contributions from their hospital pharmacy colleagues to deliver the fundamentals of AMS (following appropriate education and training from the specialist pharmacists themselves), and also to identify patients that require more specialist input. However, although these activities are well-described, good-quality evidence of their impact on optimizing antimicrobial therapy and patient outcomes is sadly lacking. Improving this evidence-base forms one of the future aspirations of the specialty, utilizing upcoming developments in data capture to take this forward (see below).

In comparison to the hospital sector, there are very few dedicated antimicrobial specialist pharmacist roles in primary care in the UK. A survey carried out in 2014 identified that, in $66 \%$ of primary care organizations, AMS roles were led by generalist prescribing advisors/ medicine management pharmacists [63]. AMS activities of pharmacists in primary care are similar to those in secondary care in respect to guideline writing, audit, education, monitoring and feedback; often teams link with hospital microbiology laboratories for clinical infection advice. Given that over $85 \%$ of antimicrobials are prescribed outside the hospital sector in the UK [41], and with the increasing emphasis on a 'One Health' approach to tackling AMR [27], cross-sector AMS programs, where primary and secondary care specialists work together to improve prescribing across a regional population, are likely to become the norm over the coming years. There are already some examples of cross-sector working in select regions of the UK, where specialist antimicrobial pharmacists from both sectors work on collaborative projects to improve antimicrobial use.

In Scotland, antimicrobial pharmacists have a remit for hospital and community care and work closely with prescribing advisers to influence general practitioners antibiotic prescribing behaviors. The national network of antimicrobial pharmacists works closely with SAPG to support the national stewardship program and, in addition, they have their own annual work plan of quality improvement initiatives.

\section{THE CHANGING HEALTHCARE LANDSCAPE: AN OPPORTUNITY FOR ANTIMICROBIAL PHARMACISTS?}

Creating national infrastructures and technologies to help support AMS development has been important for UK antimicrobial pharmacists and their teams. The tools already discussed have provided opportunities particularly at a local level for teams to review, develop, implement and encourage AMS strategies. However, the challenge is how to adapt local stewardship programs to the evolving, changing healthcare landscape that is the NHS. Below, are a few scenarios of where UK pharmacists are becoming involved in more novel stewardship activities.

\section{Electronic Systems}

Although there is an extensive literature on the positive contribution that electronic systems (such as computerized clinical decision support, 
computerized physician order entry or full EP) can provide to AMS, the bulk of this originates from the USA, South East Asia, and Australia, where such systems have been in use for many years [64-68]. EP is not yet widely implemented in the UK, although a handful of pathfinder hospitals have had experience with EP systems for a considerable time [69]. Furthermore, although the potential benefits from introduction of EP have long been recognized $[70,71]$, little work has so far been published on the actual impact of these systems on antimicrobial usage and resistance. Four small case studies have reported on the impact of electronic systems in AMS in the UK [72-75] demonstrating decreased levels of antimicrobial usage [72], increased identification of patients requiring intervention [73], avoidance of clinically significant drug interactions [74] and improvements in documentation of key antimicrobial indicators (such as indication and duration, which feature in the Start Smart, Then Focus toolkit) [75].

Around 15 different providers of EP systems are active within the UK market, and these products are being used in about $20 \%$ of NHS Trusts, with an expectation that $40-50 \%$ of Trusts will have a plan for implementation of EP in place by 2016 [76]. With this large number of different solutions and timelines for implementation, there will inevitably be significant variation in how EP is used to support AMS. There is an on-going research program investigating how EP is introduced into NHS Trusts which will include work looking at effectiveness (primarily safety considerations around drug-drug interactions or allergy awareness) and outcomes [76]. Work is beginning, with the formation of ESPAUR, to help guide NHS Trusts in their procurement and implementation plans for EP, with specific reference to their use in AMS. It is to be expected that, as EP systems and their use in stewardship matures within the UK, an increasing evidence base will become available, highlighting additional beneficial outcomes (and potential pitfalls).

A further step change in the benefits of EP for stewardship will be achieved by implementation of mobile technologies harnessing EP, biochemical and microbiological results, patient observations, radiology, and clinical decision support in a single point-of-care device. There are a large number of antimicrobial smartphone apps available within the UK, commonly providing information on preferred antimicrobial choices for specific indications, but, as this field also matures, the exciting possibilities provided by linking these apps with the many data sources available to support clinical decision making will drive innovation and research in this area.

\section{Antifungal Stewardship Initiatives}

Despite the low incidence of invasive fungal infections compared to bacterial infections, for some specialist centers antimicrobial expenditure is dominated by antifungal use. While strategies have focused on the prudent use of antibiotics, antifungal stewardship is less well defined. This is primarily due to a lack of effective diagnostics to guide therapy, of therapeutic drug monitoring to guide dosing and of knowledge of the funding arrangements for antifungals. Antifungal stewardship initiatives are gaining momentum in the UK at present with pharmacists driving the agenda. One such program [77] has suggested savings of approximately $£ 180,000$ over a 12-month period by rationalizing and reviewing therapies, while another two programs [77, 78] found stepping down and stopping unnecessary empiric therapy was common. 


\section{Outpatient Parenteral Antimicrobial Therapy}

Over recent years, there has been a drive to treat patients closer to their own home, facilitating early discharge or even avoiding admission altogether. For antimicrobials, outpatient parenteral antimicrobial therapy (OPAT) offers a safe and effective (clinically and financially) [79] means to deliver treatment outside the inpatient setting, providing good clinical governance and AMS practices are in place [80, 81]. Pharmacists have been cited as core members of the OPAT team in both the adult and pediatric UK OPAT good practice recommendations $[81,82]$. This has led to a number of pharmacists taking national roles in this area, particularly addressing the stewardship dilemma that OPAT presents where the convenience of dosing antimicrobials to suit OPAT may take precedence over the spectrum of activity [80].

\section{SUMMARY}

In summary, antimicrobial pharmacists in the UK have significantly increased in number and greatly contributed to large reductions in selected HCAIs over the last decade. They are also instrumental in meeting the actions set out by the UK AMR Strategy, with significant progress made toward several of the key areas for action. Improving the evidence base through research, developing novel stewardship strategies and strengthening national and international networks are areas where UK antimicrobial pharmacists must concentrate their efforts in the coming years. We look forward to working collaboratively with a wider, international, group of colleagues in the future.

\section{ACKNOWLEDGMENTS}

This supplement was not sponsored by outside commercial interests. No source of funding was received for publication of this article. All named authors meet the International Committee of Medical Journal Editors (ICMJE) criteria for authorship for this manuscript, take responsibility for the integrity of the work as a whole, and have given final approval to the version to be published. All authors were involved in writing this manuscript.

Conflict of interest. M.G. serves on the BSAC UK OPAT Initiative Steering Group. M.G. receives reimbursement of travel expenses only from the BSAC for attending and speaking at the UK OPAT Workshop Series and related events. M.G. reports attending advisory boards for The Medicines Company, Clinigen, Astellas Pharmaceuticals and Cubist/ Merck and receiving educational travel and speaker grants from Eumedica Pharmaceuticals and Astellas Pharmaceuticals, Sanofi, respectively. P.W. has received fees for advisory boards, speaker honoraria or educational grants from Astellas Pharmaceuticals, Baxter, Clinigen, Cubist, Eumedica, ICNet, and Pfizer. D.A.O reports attending advisory boards for Cubist and Merck Sharpe Dome (unpaid/paid to organization) and speaker honorarium to Antimicrobial Pharmacists training program led by antimicrobials pharmacists, supported by Astellas Pharmaceuticals. P.H. reports attending advisory boards for Astellas Pharmaceuticals, Baxter/ICNET, Cubist/Merck, Gilead, GSK, Novartis, Pfizer, Sanofi and receiving educational travel and speaker grants from Astellas Pharmaceuticals B.Braun, Eumedica Pharmaceuticals, Gilead. J.S. 
received a speaker honorarium from bioMerieux UK for a national Microbiology meeting. L.W. has received fees for advisory boards, speaker honoraria or travel expenses from Astellas Pharmaceuticals, Cubist/Merck, Gilead, Pfizer, and UKCPA. H.W. has received fees for consultancy, advisory boards or travel expenses from Astellas Pharmaceuticals, AstraZeneca, Basilea/Quintiles, Bayer, Cubist/ MSD, Roche, Pfizer, UKCPA, ECDC and BSAC.

Compliance with ethics guidelines. This article does not contain any new studies with human or animal subjects performed by any of the authors.

Open Access. This article is distributed under the terms of the Creative Commons Attribution-NonCommercial 4.0 International License (http://creativecommons.org/licenses/ by-nc/4.0/), which permits any noncommercial use, distribution, and reproduction in any medium, provided you give appropriate credit to the original author(s) and the source, provide a link to the Creative Commons license, and indicate if changes were made.

\section{REFERENCES}

1. Department of Health. Getting ahead of the curve: a strategy for combating infectious diseases (including other aspects of health protection). 2002.

2. Department of Health. Winning ways: working together to reduce healthcare associated infection in England. 2003.

3. National Audit Office. Reducing healthcare associated infections in hospitals in England. 2009.

4. Department of Health. Annual epidemiological commentary: mandatory MRSA, MSSA and E. coli bacteraemia and $C$. difficile infection data. 2013/14.

5. Department of Health. Bloodborne MRSA infections rates to be halved by 2008. http:// webarchive.nationalarchives.gov.uk/+/www.dh. gov.uk/en/Publicationsandstatistics/Pressreleases/ DH_4093533.

6. Department of Health. The operating framework for the NHS in England 2008/09 http://webarchive. nationalarchives.gov.uk/20130107105354/http:// www.dh.gov.uk/prod_consum_dh/groups/dh_dig italassets/@dh/@en/documents/digitalasset/dh_08 1271.pdf.

7. Department of Health. PL CMO (2003) 3: Hospital Pharmacy initiative for promoting prudent use of antibiotics in hospitals. 2003.

8. Wickens HJ, Jacklin A. Impact of the hospital pharmacy Initiative for promoting prudent use of antibiotics in hospitals in England. J Antimicrob Chemother. 2006;58:1230-7.

9. Hand K. Antibiotic pharmacists in the ascendancy. J Antimicrob Chemother. 2007;60(Suppl 1):i73-6.

10. Ansari F, Gray K, Nathwani D, et al. Outcomes of an intervention to improve hospital antibiotic prescribing: interrupted time series with segmented regression analysis. J Antimicrob Chemother. 2003;52:842-8.

11. Wickens HJ, Robson R, Griffiths T. A web-based pharmacy to microbiology referral system. Hosp Pharm. 2006;13:131-2.

12. Weeks C, Jones G, Wylie S. Costs and health care benefits of an antimicrobial management programme. Hosp Pharm. 2006;13:179-82.

13. Talpaert MJ, Rao GG, Cooper BS, Wade PA. Impact of guidelines and enhanced antibiotic stewardship on reducing broad-spectrum antibiotic usage and its effect on incidence of Clostridium difficile infection. J Antimicrob Chemother. 2011;66:2168-74.

14. Thakkar K, Gilchrist M, Dickinson E, Benn J, Franklin BD, Jacklin A, et al. A quality improvement programme to increase compliance with an anti-infective prescribing policy. J Antimicrob Chemother. 2011;66:1916-20.

15. Department of Health. Saving lives-high impact intervention. Care bundle to reduce Clostridium difficile. 2007.

16. Department of Health. Clostridium difficile infection: how to deal with the problem. 2008.

17. Public Health England. Clostridium difficile: what it is, how to prevent, how to treat. 2009.

18. Health Protection Agency. Clostridium difficile infection (CDI): management in care homes. 2010. 
19. Department of Health. Clostridium difficile: updated guidance on diagnosis and reporting. 2012.

20. NHS England. Clostridium difficile infection objectives for NHS organisations in 2014/15 and guidance on sanction implementation.

21. NHSScotland Performance. HEAT Targets due for delivery 2006/07-2014/15. http://www.gov.scot/ Resource/0046/00467027.pdf.

22. Health Protection Scotland. Commentary of quarterly epidemiological data on Clostridium difficile infection (CDI) and Staphylococcus aureus bacteraemias (SAB) in Scotland. January to March (Q1) 2015. http://www.documents.hps.scot.nhs.uk/ hai/sshaip/publications/quarterly-epidemiologicalcommentaries/2015/2015-q1-sab-cdi-commentary. pdf.

23. Scottish Antimicrobial Prescribing Group. Progress report for 2008-2011. https://www.scottishmedi cines.org.uk/files/sapg/SAPG_Progress_Report_200811.pdf.

24. Royal College of General Practitioners. TARGET Antibiotics Toolkit [cited 2015 15/07/2015]. http:// www.rcgp.org.uk/clinical-and-research/target-anti biotics-toolkit.aspx.

25. Department of Health. Antimicrobial stewardship: Start smart-then focus. 2011.

26. Public Health England. Start smart-then focus: antimicrobial stewardship toolkit for English hospitals. 2015.

27. Department of Health. Annual progress report and implementation plan (2014) of the UK AMR Strategy 2013-18. 2014.

28. Dellit TH, Owens RC, McGowan JE Jr, Gerding DN, Weinstein RA, Burke JP, et al. Infectious Diseases Society of America and the Society for Healthcare Epidemiology of America guidelines for developing an institutional program to enhance antimicrobial stewardship. Clin Infect Dis. 2007;44(2):159-77.

29. Dumartin C, Rogues AM, Amadeo B, Pefau M, Venier AG, Parneix $P$, et al. Antibiotic usage in south-western French hospitals: trends and association with antibiotic stewardship measures. J Antimicrob Chemother. 2011;66(7):1631-7.

30. Fridkin SK, Srinivasan A. Implementing a strategy for monitoring inpatient antimicrobial use among hospitals in the United States. Clin Infect Dis. 2014;58(3):401-6.

31. Chen AW, Khumra S, Eaton V, Kong DC. Snapshot of barriers to and indicators for antimicrobial stewardship in Australian Hospitals. J Pharm Pract Res. 2011;41(1):37-41.

32. NHS Business Services Authority. http://www. nhsbsa.nhs.uk/Index. Accessed Aug 2015.

33. Health and Social Care Information Centre. Prescribing measures, indicators and comparators. 2015. http://www.hscic.gov.uk.

34. Health and Social Care Information Centre. Medicines Optimisation Key Therapeutic Topics Comparators 2015/16. 2015. http://www.hscic.gov.uk.

35. National Institute for Health and Care Excellence. Medicines management options for local implementation. 2015. http://www.nice.org.uk/ Media/Default/About/what-we-do/NICE-advice/Keytherapeutic-topics/compiled\%20KTT\%20Document_ final_March\%202015\%20amend.pdf.

36. Department of Health. ARHAI 5th Annual Report, April 2013-March 2014. 2014. https://www.gov.uk/ government/uploads/system/uploads/attachment_ data/file/405295/ARHAI_annual_report.pdf.

37. Department of Health. Minutes of ARHAI Twenty-Fifth Meeting on 03 July 2014. 2014. https://app.box.com/ARHAI-Minutes-Papers/1/251 0541487/21452112235/1.

38. NHS England. Quality Premium: 2015/16 guidance for CCGs. 2015. http://www.england.nhs.uk/wpcontent/uploads/2015/04/qual-prem-guid-1516.pdf.

39. NHS PrescQIPP. Antibiotic QP prescribing report for 2014/15 launched. http://www.prescqipp.info/news feed/antibiotic-qp-prescribing-report-for-2014/15.

40. NHS National Services Scotland, Scottish Antimicrobial Prescribing Group. Primary Care Prescribing Indicators Annual Report 2013-2014. https://isdscotland.scot.nhs.uk/Health-Topics/Pres cribing-and-Medicines/Publications/2014-10-14/ 2014-10-14-SAPG-Primary-Care-PI-2013-14-Report. pdf?18948000670.

41. Public Health England. English surveillance programme for antimicrobial utilisation and resistance (ESPAUR) Report 2014. http://www.gov. uk/government/uploads/system/uploads/attachment _data/file/362374/ESPAUR_Report_2014_3_.pdf.

42. Howard P, Pulcini C, Levy Hara G, West RM, Gould IM, Harbarth $S$, et al. An international cross-sectional survey of antimicrobial stewardship programmes in hospitals. J Antimicrob Chemother. 2015;70:1245-55.

43. Howard P, Pulcini C, Levy Hara G, Nathwani D, Gould I. Global antimicrobial stewardship surveyinterim analysis of UK data. Oral paper 2087. 
Birmingham: Federation of Infection Societies; 2013.

44. $\mathrm{Rx}$ Info. Define-measure prescribing practices against those of neighbouring hospitals: Rx_Info; 2015 [cited 2015 15/Jul/2015]. http://www.rx-info. co.uk/products/define.ashx.

45. NHS National Services Scotland, Report on Antimicrobial Use and Resistance in Humans in 2013. https://isdscotland.scot.nhs.uk/Health-Topics/ Prescribing-and-Medicines/Publications/2015-01-27/ 2015-01-27-SAPG-2013-Report.pdf?86472719908.

46. Public Health Wales. Reports of the Welsh Antimicrobial Resistance Programme. 2015. https://www.wales.nhs.uk/sites3/page.cfm?orgId= $457 \&$ pid=28906.

47. Health Social Care Northern Ireland. COMPASSGeneral Practice prescribing information service. 2015. http://www.hscbusiness.hscni.net/services/ 2163.htm.

48. Public Health Wales. Antimicrobial Stewardship: "Start Smart-Then Focus": Guidance for Antimicrobial Stewardship for Hospitals in Wales. 2011. http://www.wales.nhs.uk/sitesplus/documents/ 888/Public\%20Health\%20Wales\%20Antimicrobial\% 20Stewardship\%20Guidance.pdf.

49. Scottish Antimicrobial Prescribing Group, Quality Improvement. http://www.scottishmedicines.org. uk/SAPG/Quality_Improvement/Quality_Improve ment. Accessed Aug 2015.

50. National Institute for Health and Care Excellence. Antimicrobial Stewardship 2015. https://www.nice. org.uk/guidance/indevelopment/gidantimicrobialstewardship. Accessed Aug 2015.

51. Ashiru-Oredope D, Cookson B, Fry C, on behalf of the Advisory Committee on Antimicrobial R, Healthcare Associated Infection Professional Education S. Developing the first national antimicrobial prescribing and stewardship competences. J Antimicrob Chemother. 2014;69:2886-8.

52. Sneddon J, Gilchrist M, Wickens H. Development of an expert professional curriculum for antimicrobial pharmacists in the UK. J Antimicrob Chemother. 2015;70:1277-80.

53. Wickens H, Farrell S, Jacklin A, Ashiru-Oredope D, Holmes A. Who trains the trainer? Education of antimicrobial pharmacists. Poster 137. Birmingham: Federation of Infection Societies; 2013.

54. Simpson SA, Butler CC, Hood K, Cohen D, Dunstan F, Evans MR, et al. Stemming the Tide of Antibiotic Resistance (STAR): a protocol for a trial of a complex intervention addressing the 'why' and 'how' of appropriate antibiotic prescribing in general practice. BMC Fam Pract. 2009;10:20.

55. UK Medical Research Council. The STAR Programme (Stemming the tide of antimicrobial resistance) 2005 [cited 2015 15/07/2015]. http:// www.stemmingthetide.org/.

56. Butler CC, Simpson SA, Dunstan F, Rollnick S, Cohen D, Gillespie D, et al. Effectiveness of multifaceted educational programme to reduce antibiotic dispensing in primary care: practice based randomised controlled trial. BMJ. 2012;344:d8173.

57. NHS Education for Scotland. Scottish Reduction in Antimicrobial Prescribing (ScRAP) Programme. 2013. http://www.nes.scot.nhs.uk/education-andtraining/by-discipline/pharmacy/about-nes-pharm acy/educational-resources/resources-by-topic/infec tious-diseases/antibiotics/scottish-reduction-in-anti microbial-prescribing-(scrap)-programme.aspx.

58. NHS Education for Scotland. Antimicrobial stewardship educational workbook, NHS Education for Scotland. 2015. http://www.nes. scot.nhs.uk/media/3239839/final_antimicrobial_ stewardship_workbook.pdf.

59. Wickens HJ, Farrell S, Ashiru-Oredope DA, Jacklin A, Holmes A, In collaboration with the Antimicrobial Stewardship Group of Department of Health Advisory Committee on Antimicrobial Resistance and Health Care Associated Infections (ASG-ARHAI). The increasing role of pharmacists in antimicrobial stewardship in English hospitals. J Antimicrob Chemother. 2013;68(11):2675-81.

60. Jepson A, Wickens H. What does a microbiology pharmacist do? Pharm J. 2003;271:774-5.

61. Knox K, Lawson W, Dean B, Holmes A. Multidisciplinary antimicrobial management and the role of the infectious diseases pharmacist-a UK perspective. J Hosp Infect. 2003;53(2):85-90.

62. Standing Medical Advisory Committee, Sub-Group on Antimicrobial Resistance. The path of least resistance. Department of Health; 1998. http:// webarchive.nationalarchives.gov.uk/20080905234 748/dh.gov.uk/en/publicationsandstatistics/publi cations/publicationspolicyandguidance/dh_4009 357.

63. Ashiru-Oredope D. A survey of primary care antimicrobial pharmacists. Royal Pharmaceutical Socety conference; 2015.

64. Kullar R, Goff DA. Transformation of antimicrobial stewardship programs through technology and 
informatics. Infect Dis Clin $\mathrm{N}$ Am. 2014;28(2):291-300.

65. McGregor JC, Weekes E, Forrest GN, Standiford HC, Perencevich EN, Furuno JP, et al. Impact of a computerized clinical decision support system on reducing inappropriate antimicrobial use: a randomized controlled trial. J Am Med Inform Assoc. 2006;13(4):378-84.

66. Wang HY, Lu CL, Wu MP, Huang MH, Huang YB. Effectiveness of an integrated CPOE decision-supporting system with clinical pharmacist monitoring practice in preventing antibiotic dosing errors. Int J Clin Pharmacol Ther. 2012;50(6):375-82.

67. Sintchenko V, Coiera E, Gilbert GL. Decision support systems for antibiotic prescribing. Curr Opin Infect Dis. 2008;21(6):573-9.

68. Buising KL, Thursky KA, Robertson MB, Black JF, Street AC, Richards MJ, et al. Electronic antibiotic stewardship-reduced consumption of broad-spectrum antibiotics using a computerized antimicrobial approval system in a hospital setting. J Antimicrob Chemother. 2008;62(3):608-16 (65).

69. Baysari MT, Oliver K, Egan B, Li L, Richardson K, Sandaradura I, et al. Audit and feedback of antibiotic use: utilising electronic prescription data. Appl Clin Inform. 2013;4(4):583-95.

70. Audit Commission. A spoonful of sugar: medicines management in NHS hospitals. 2001.

71. Hitchen L. Electronic prescribing needed in hospitals to monitor use of antibiotics. BMJ. 2007;334(7596):712.

72. Curtis C, Marriott J, Langley C. Development of a prescribing indicator for objective quantification of antibiotic usage in secondary care. J Antimicrob Chemother. 2004;54(2):529-33.

73. Jumaa P, Young I, Nightingale P, Clark I. Audit of the antimicrobial treatment of Clostridium difficile toxin-positive episodes using an integrated electronic prescribing, information and communication system. J Hosp Infect. 2009;72(4): 371-3.

74. Bignardi GE, Hamson C, Chalmers A. Can we use electronic prescribing to reduce prescription errors for antibiotics? J Infect. 2010;61(5):427-8.

75. Cooley N. Personal communication (via Paul Wade) on benefits of e-prescribing from lead antimicrobial pharmacist. London: Chelsea \& Westminster NHS Foundation Trust; 2014.
76. Sheikh A. Personal communication (via Paul Wade) about level of ePrescribing in UK from Professor of Primary Care Research \& Development and Chair, eHealth Strategy Group, University of Edinburgh. 2015.

77. Micallef C, Aliyu SH, Santos R, Brown NM, Rosembert D, Enoch DA. Introduction of an antifungal stewardship programme targeting high-cost antifungals at a tertiary hospital in Cambridge, England. J Antimicrob Chemother. 2015;70(6):1908-11.

78. Parkinson C, Gilchrist M, Armstrong-James, D, Whitney L, Bicanic T. Sharing and developing a consensus approach to antifungal stewardship in London- a proof of concept (poster). Harrogate: Federation of Infection Societies; 2014.

79. Chapman ALN, Dixon S, Andrews D, Lillie PJ, Bazaz $\mathrm{R}$, Patchett JD. Clinical efficacy and cost-effectiveness of outpatient parenteral antibiotic therapy (OPAT): a UK perspective. J Antimicrob Chemother. 2009;64(6):1316-24.

80. Gilchrist M, Seaton RA. Outpatient parenteral antimicrobial therapy and antimicrobial stewardship: challenges and checklists. J Antimicrob Chemother. 2015;70(4):965-70.

81. Chapman AL, Seaton RA, Cooper MA, Hedderwick $\mathrm{S}$, Goodall V, Reed C, et al. Good practice recommendations for outpatient parenteral antimicrobial therapy (OPAT) in adults in the UK: a consensus statement. J Antimicrob Chemother. 2012;67(5):1053-62.

82. Patel S, Abrahamson E, Goldring S, Green H, Wickens $\mathrm{H}$, Laundy $\mathrm{M}$. Good practice recommendations for paediatric outpatient parenteral antibiotic therapy (p-OPAT) in the UK: a consensus statement. J Antimicrob Chemother. 2015;70(2):360-73.

83. Nathwani D, Sneddon J, Malcolm W, Wiuff C, Patton A, Hurding S, et al. Scottish Antimicrobial Prescribing Group (SAPG): development and impact of the Scottish National Antimicrobial Stewardship Programme. Int J Antimicrob Agents. 2011;38(1):16-26.

84. Social_Services_and_Public_Safety_Northern_Ireland DoH. Antimicrobial Resistance Action Committee (ARAC) [cited 2015 15/07/2015]. http://www. dhsspsni.gov.uk/health_protection-antimicrobial_ resisitance. 